\title{
Uma interpretação marxista sobre a infância e os abrigos
}

\author{
Rodrigo Silva Lima ${ }^{1}$ \\ https://orcid.org/0000-0002-5036-7471 \\ ${ }^{1}$ Universidade Federal Fluminense, Departamento de Serviço Social, Programa de Pós-Graduação em Serviço Social e \\ Desenvolvimento Regional, Niterói, RJ, Brasil
}

\section{Uma interpretação marxista sobre a infância e os abrigos}

Resumo: O objetivo desse artigo é contribuir com a produção do conhecimento na área da infância e da adolescência, a partir da produção marxiana e autores da tradição marxista. Observa-se a pouca incidência do marxismo nos estudos sobre a situação de vida crianças e adolescentes. Para além de abordagens individuais, considera-se o processo de institucionalização em abrigos uma resposta às expressões da questão social e não o descompasso das famílias da classe trabalhadora em suas funções protetivas. Essas instituições cumprem uma função na reprodução social, por meio da proteção e da coerção, assim como a preparação da mão de obra para uma inserção precarizada no mercado de trabalho, reproduzindo o ciclo de dependência institucional e a exploração.

Palavras-chave: Crianças e adolescentes. Questão social. Abrigos. Marx.

\section{A marxist interpretation on childhood and shelters}

Abstract: The article's objective is to contribute to knowledge production in the field of childhood and adolescence, based on Marxian production and authors of Marxist tradition. There is a low incidence of Marxism in studies on life situation of children and adolescents. In addition to individual approaches, the institutionalization process in shelters is considered to be an answer to the expressions of the social issue and not the disadvantage of working-class families in their protective functions. These institutions play a role in social reproduction, through protection and coercion, as well as preparing the workforce for a precarious insertion in the labor market, reproducing the cycle of institutional dependence and exploitation. Keywords: Children and adolescents. Social question. Shelters. Marx.

Recebido em 01.07.2020. Aprovado em 08.09.2020. Revisado em 14.10.2020.

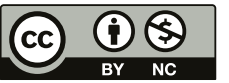

Este é um artigo publicado em acesso aberto (Open Access) sob a licença Creative Commons Attribution NonCommercial, que permite uso, distribuição e reprodução em qualquer meio, sem restrições desde que sem fins comerciais e que o trabalho original seja corretamente citado. 


\section{Introdução}

A infância ${ }^{1}$ como uma categoria de análise estrutural exige dos pesquisadores da área das ciências sociais aplicadas enfoques distintos daqueles estudos tradicionalmente centrados no desenvolvimento individual, cognitivo e nas etapas do crescimento já identificados pela psicologia. As correntes funcionalistas subestimaram o valor da infância dirigindo suas investigações para dimensões da socialização e da relação familiar e aquelas pesquisas inspiradas na perspectiva crítico-dialéticas, que estudaram a estrutura de classes, não atribuíram tanta relevância ao papel desempenhado por crianças e adolescentes no capitalismo (PILOTTI, 1995).

As constatações de Pilotti, realizadas há mais de duas décadas não foram totalmente alteradas, porém verifica-se maior preocupação entre pesquisadores, trabalhadores e militantes em produzir e disseminar informações e conhecimento sobre o papel desempenhado por crianças e adolescentes na sociedade, seja abordando as múltiplas determinações que produzem a situação de rua (RIZZINI, 2003); os formatos perversos de instituições privativas de liberdade (SILVA, 2011; SALES, 2007); seja com a crítica à exploração sexual (SANTOS, 2010); do trabalho infantil (NEVES, 1999) ou com as disputas em torno do fundo público (SALVADOR; ALVES, 2012; LIMA, 2015).

Contudo, nas duas últimas décadas, as publicações relacionadas às medidas protetivas em regimes de abrigo, principalmente por parte de assistentes sociais, têm sido inexpressivas. Em levantamento realizado por Malfitano e Silva (2014) são sinalizados questionamentos pelo fato de, entre 1990 e 2009, não serem identificadas revistas de Serviço Social ${ }^{2}$ com a divulgação de conhecimento sobre abrigos ${ }^{3}$. Embora, nessa área, a produção intelectual e os referenciais da psicologia sejam hegemônicos, mesmo que tardiamente é possível conjugar as dimensões teóricas e políticas de Marx, adotadas na direção estratégica da formação em Serviço Social, com a produção do conhecimento sobre os processos de institucionalização da infância pauperizada.

Na primeira seção deste artigo, diante da pouca incidência do marxismo nos estudos sobre a infância pauperizada, será realizada uma releitura da Lei Fabril e da Lei Geral da Acumulação. Na segunda seção, o processo de institucionalização em abrigos aparece como resposta do Estado às expressões da questão social e não como descompasso das famílias da classe trabalhadora em suas funções protetivas. Essas instituições cumprem uma função na reprodução social, por meio da proteção e da coerção, assim como a preparação da mão de obra para uma inserção precarizada no mercado de trabalho, reproduzindo o ciclo de dependência institucional e a exploração.

\section{Pauperização e a situação da infância no capitalismo}

O cenário dramático exposto por Marx $(1983,1984)$, em O Capital demonstra aos pesquisadores das ciências sociais aplicadas que as contradições entre o capital e o trabalho assim como a necessidade de superação da questão social ${ }^{4}$ continuam na ordem do dia. Para analisar o significado da questão social, o referencial crítico, inspirado em Marx e na tradição marxista, merece destaque por salientar não apenas as contradições, como também as desigualdades da sociedade, não se restringindo às determinações filosóficas que buscam compreender a realidade, mas, sobretudo, transformá-la.

A condição de vida da classe trabalhadora na Europa, nos últimos anos do século XVIII, foi marcada pelo fenômeno do pauperismo e, de acordo com Paulo Netto (2001, p. 42): "constituiu o aspecto mais imediato da instauração do capitalismo em seu estágio industrial-concorrencial". O pauperismo constituía um fenômeno aparentemente novo e se as desigualdades e a existência de ricos e pobres na sociedade era uma característica de longa data, por outro lado as contradições e antagonismos entre capital e trabalho ficavam ainda mais evidentes, pois embora existisse uma capacidade crescente da produção de riqueza, a pobreza também aumentava significativamente (PAULO NETTO, 2001).

Em O Capital (MARX, 1983;1984), a brutalidade da denúncia sobre os abusos, a estupidez punitiva e a voracidade por mais trabalho dos proprietários, por meio de expedientes torpes e essenciais ao prolongamento da jornada de trabalho, para além da crítica, impulsionou as classes subalternizadas a resistir e lutar por melhores condições de vida. No tocante à preservação dessas condições, a sanha capitalista contribuiu progressivamente: (1) para o encurtamento da vida - mortalidade real e dissimulada - de parcelas de crianças e adolescentes da classe trabalhadora; (2) produziu epidemias; e (3) dilacerou famílias inteiras. A exploração contínua da força 
de trabalho imprimiu um ritmo extenuante às crianças e, principalmente, aos adolescentes, com uma rigidez dificilmente observada no trato dos adultos e/ou até mesmo dos sujeitos escravizados (MARX, 1983).

Além disso, o trabalho assalariado subjugou a integridade infantil e sua compleição física ao deslocar esse público para trabalhos insalubres, em espaços úmidos, empoeirados, abafados e com resíduos nocivos à respiração, resultando na diminuição progressiva da estatura média dos adultos e, consequentemente, dos soldados, um problema para as forças militares. Esse processo de trabalho desumano favoreceu o uso de substâncias inebriantes como o ópio e as bebidas alcoólicas para aplacar a dor e o cansaço diante de jornadas de trabalho longas e fatigantes. Submetidos a cobranças desmedidas, essa exploração descaracterizou as singelas linhas faciais infantis por um semblante rudimentar, que causava ojeriza e repugnância e desaguou, com isso, no aligeirado processo de envelhecimento, com o desgaste e a atrofia da musculatura e a redução da energia física e mental, comprometendo a utilização dos membros corporais e a capacidade para o trabalho (MARX, 1983).

Os médicos, nos exames de ceramistas, diagnosticavam a degeneração, do ponto de vista físico e moral, além de esses trabalhadores apresentarem quadros severos de deformação física, raquitismo, anemias, reumatismo, perturbações hepáticas e renais, pneumonia, bronquite e doenças específicas provenientes da manipulação das cerâmicas. A sociedade possui civilização excedente e, como peças de reposição de uma engrenagem, homens, mulheres e crianças, são explorados, descartados, reutilizados ao gosto e a contragosto de quem tem o poder sobre suas vidas: "o prolongamento da jornada de trabalho, além dos limites do dia natural por noite adentro serve apenas de paliativo, apenas mitiga a sede vampiresca por sangue vivo do trabalho" (MARX, 1983, p. 206).

Um documento encaminhado ao comissário de emprego infantil, pelo médico Charles Parsons (apud MARX, 1983), merece destaque, pois embora não naturalize a exploração da mão de obra, por outro lado, também termina por culpabilizar a família por violências e violações: "posso falar com base somente em observações pessoais não estatísticas, mas nem por isso posso deixar de afirmar que sentia mais e mais revolta ao ver essas pobres crianças, cuja saúde foi sacrificada para satisfazer a avareza de seus pais e de seus empregadores" (MARX, 1983, p. 198).

Liminarmente, ao identificar o conteúdo dos relatórios das inspetorias de fábrica e o surgimento da legislação fabril, Marx (1983, p. 220-221), explicitou com contundente crítica, os aspectos da exploração da força de trabalho, da ampliação do pauperismo e da sociabilidade destrutiva do capital. A legislação fabril, compreendida entre os anos de 1833 e 1864, instituía uma jornada absurda de 15 horas diárias ${ }^{5}$ de trabalho. Para crianças entre 09 e 13 anos de idade, a atividade laborativa foi limitada em oito horas diárias e não poderia ser realizada entre oito e meia da noite e cinco e meia da manhã - se somente essas informações podem ser consideradas um disparate, uma afronta, cabe salientar que, antes da lei fabril de 1833 , as crianças e adolescentes extrapolavam todos os limites impostos e trabalhavam o dia e/ou a noite toda (MARX, 1983).

Nas considerações sobre mais-valia relativa percebe-se que uma das críticas marxianas reside na problematização acerca do uso da maquinaria e de sua finalidade, à medida que, no desenvolvimento das forças produtivas e na explicação sobre o resultado de alívio do esforço diário de um trabalhador na produção de mercadorias, a maquinaria apresenta fundamental importância para intensificação, ampliação da jornada e exploração sistemática dessa força de trabalho. Ou seja, a maquinaria se destinava a "baratear mercadorias e encurtar a parte da jornada de trabalho que o trabalhador precisa para si mesmo, a fim de encompridar a outra parte da sua jornada de trabalho que ele dá de graça para o capitalista. Ela é meio de produção de mais-valia" (MARX, 1984, p. 7).

Com essa descoberta, Marx desvenda as diferenças fundamentais engendradas no modo de produção, entre a ferramenta e a máquina; a manufatura e a grande indústria; entre o proprietário dos meios de produção e as pessoas que vendem a mercadoria força de trabalho. Ressalta-se que homens e mulheres também são apropriados diferentemente, de acordo com a utilização de sua mão de obra ou da natureza de um determinado processo de trabalho. Um determinado meio de trabalho pode ser ferramenta, se for movido pela mão de um único trabalhador, ou máquina, se for movido por um determinado tipo de recurso energético: "considerada exclusivamente como meio de baratear o produto, o limite para o uso da maquinaria está em que sua própria produção custe menos trabalho do que sua aplicação substitui” (MARX, 1984, p. 21).

A conversão do trabalho em trabalho assalariado ou o tratamento apartado entre o resultado de determinado trabalho e o trabalho propriamente dito, ou seja, a divisão entre sujeito e objeto, demarca a linha inicial do 
processo de produção e, mais diretamente, da reprodução social simples. Sendo assim, "a separação entre o produto do trabalho e o próprio trabalho, entre as condições objetivas do trabalho e sua força subjetiva de trabalho, era a base realmente dada, o ponto de partida do processo de produção capitalista" (MARX, 1984, p. 156). Os processos subjetivos, os cuidados familiares ${ }^{6}$ com as crianças e adolescentes, os dilemas impostos pela esfera do consumo, todos esses aspectos, praticamente, não são levados em consideração pelos detentores dos meios de produção, sendo que "a compra de força de trabalho com dinheiro dá ao capitalista certos direitos de dispor do trabalho dos outros sem considerar necessariamente o que estes possam pensar, precisar ou sentir" (HARVEY, 2000, p. 101).

A ideologia liberal que reforça a moral do trabalho e a culpabilização individual das famílias pauperizadas da classe trabalhadora ${ }^{7}$, sob o discurso conservador reproduzido por frases popularizadas do tipo: "mente vazia é oficina..." ou "é melhor trabalhar do que fazer besteira...", desconhecem o caráter alienante do modo de produção capitalista e a impossibilidade de todos terem acesso igualitário às oportunidades de emprego e escolarização. A essência dessa questão é descortinada ao invertermos o ponto de partida do abuso e da exploração "é o modo de exploração capitalista que fez do poder paterno, ao suprimir sua correspondente base econômica, um abuso" (MARX, 1984, p. 91).

\section{A funcionalidade dos abrigos no capitalismo}

A infância pauperizada, geralmente encaminhada para as casas de trabalho ou workhouses, necessitava de algum formato de proteção. Diante dos efeitos nocivos do processo de desenvolvimento urbano industrial na Europa era submetida aos infortúnios e vicissitudes da vida, corriam risco de morte, pois, muitas vezes, não tinham acesso às condições mínimas de sobrevivência, como comida, bebida e habitação .

Em países liberais era inadmissível a ajuda aos pobres, sendo permitida em raras exceções, porque a intervenção estatal era considerada antinatural e inibia a disputa entre os indivíduos no mercado, condição de preparação para enfrentar os desafios postos à humanidade. Dessa forma, o progresso, concebido dentro das leis da natureza, resultava da positividade dos conflitos e de um processo de seleção natural, por meio da constante luta entre indivíduos sociais, "luta essa que tinha uma natural função seletora [...] o fraco, o doente, o malformado, o ocioso, o imprudente, o imprevidente - que não se adaptaram às formas de vida civilizada - deveriam ser impedidos de se reproduzir" (PEREIRA, 2000, p. 107). Alguns autores (POLANYI, 1980; HUBERMAN, 2008) recuperam um determinado período histórico, que antecede o século XVIII, fundamental para compreender as violências ${ }^{9}$, as origens da pobreza ${ }^{10}$, as formas de intervenção do Estado, por meio de leis e da repressão.

Nas paróquias que administravam recursos ínfimos para o atendimento do público em questão havia um misto de orgulho e resignação que, além de não questionar a petição de miséria das pessoas, apontava apenas a rigidez utilizada para lidar com a economia e a façanha de manter, mesmo com escassez de quadro trágico do proletariado emergente recursos, a obra assistencial (LONDON, 2004). Comparativamente, a remuneração de um trabalhador com um número substantivo de membros na família era, ainda assim, mais reduzida do que o orçamento per capita destinado ao mesmo número de pessoas atendidas nos asilos dos pobres.

Ao desvendar e divulgar o orçamento dessas instituições na Inglaterra do século XIX, Jack London (2004) realizou, indiretamente, uma crítica relevante à economia política, ao alívio da pobreza e, ao mesmo tempo, aos abrigos, esses espaços de convivência funcionais aos interesses do capital e constituídos por orçamentos mascarados e misteriosos (LIMA, 2015). É impossível descartar o papel desempenhado pela administração pública e os fatores que influenciaram as tendências de planejamento naquela época, pois a ideologia liberal era a base do Estado burguês em ascensão.

A justificativa para a utilização de recursos tão reduzidos não se dava exclusivamente por uma criminosa gestão ou um problema na burocracia, como apontou London, tampouco pela situação da pobreza em si, pois muitos trabalhadores eram pauperizados, mas fundamentalmente por uma ideologia que reforçava o direcionamento de uma mão invisível no curso natural das coisas ou uma espécie de darwnismo pedagógico que contemplasse um processo de seleção natural dos indivíduos de acordo com o perfil do público-alvo de atendimento ${ }^{11}$. Sobre a fome, a pobreza e a maneira de gerir os recursos financeiros dos abrigos tem-se a seguinte ponderação: 
E sabemos que cinco homens são capazes de produzir pão para mil pessoas; que um trabalhador pode produzir roupa de algodão para 250 pessoas [...]. A renda é suficiente, mas há algo criminosamente errado na administração. Quem ousaria dizer que essa enorme casa não é criminosamente administrada, quando cinco homens podem produzir pão para mil, e ainda assim milhões não têm o que comer? (LONDON, 2004, p. 303-304).

No modo de produção capitalista as instituições asilares ou abrigos ${ }^{12}$ para crianças e adolescentes cumprem determinações contraditórias que envolvem: a dimensão assistencial, educativa, coercitiva, protetora, tudo ao mesmo tempo. Isso, porém, não significa necessariamente que sua função primordial seja apenas a de assistir, educar, vigiar, controlar e proteger. A moral do trabalho e a oposição à assistência, argumentos presentes na tradição liberal, na consolidação de uma economia de mercado (PEREIRA, 2000), embora tenham suscitado intervenções assistenciais residuais e focalizadas, jamais foram pensadas para garantir a liberdade plena ou potencializar qualquer tipo de emancipação.

A moral do trabalho, que caracterizou o liberalismo, privilegiava que o acesso à alimentação, ao vestuário e ao lazer fosse garantido por meio do assalariamento dos membros da família em condições de vender a força de trabalho, inclusive as crianças. Nos abrigos isso não era considerado um direito, mas retribuído por meio da imposição do trabalho forçado, como contrapartida. A aquisição aos bens de consumo e às necessidades sociais, por parte das crianças e adolescentes, era muitas vezes fruto de um salário adquirido por familiares ou até mesmo pelos eles próprios no processo de compra e venda da força de trabalho.

Ressalte-se que do momento em que crianças, oriundas da classe trabalhadora, eram alijadas do processo de venda da força de trabalho para a indústria emergente, reduziam-se as formas de sociabilidade, pois escolas inexistiam ou eram insuficientes; a ajuda paroquial, peremptoriamente, diminuída; e a família, engolfada em jornadas de trabalho extenuantes, era, cada vez mais, destituída de suas funções afetivas, educativas, assistenciais e protetivas. Nesse sentido, em momentos históricos, as ruas se apresentavam como uma alternativa de sobrevivência, embora, em determinadas circunstâncias - como no período de introdução da maquinaria nas indústrias - mulheres e crianças, por constituírem a mão de obra mais barata, sustentassem os homens adultos da família (ENGELS, 2010).

Em casas com muitas crianças, os filhos com idades mais avançadas ficavam com a incumbência de cuidar dos mais novos. E, para manter essas crianças sossegadas, muitas vezes, eram empregados narcóticos responsáveis por convulsões que levavam à morte. Como os laços de amor e cuidado, em uma realidade avassaladoramente precária, praticamente inexistiam e se existiam eram extirpados da sociabilidade, evidenciavam-se efeitos desagregadores nas relações afetivas e familiares que terminavam por se pautar monetariamente, de forma que a família se transformava, em algumas circunstâncias, em uma instituição que poderia ser trocada por qualquer outra coisa: "em suma, os filhos se autonomizam, considerando a casa paterna como uma pensão, que pode ser trocada por qualquer outra se não lhes agrada" (ENGELS, 2010, p. 182)

A situação da infância nas instituições de trabalho forçado, que funcionavam como prisões, expressava as contradições entre capital e trabalho atenuando as manifestações da questão social e principalmente os acentuados níveis de pauperização. Na Europa, por volta de 1840, com o fim dos subsídios para os pobres, houve uma expansão do sistema de workhouses (MAURIEL, 2011, p. 47). Na capital da Inglaterra, 2\% de toda a população ${ }^{13}$ precisavam pagar por abrigo nos albergues noturnos, uma espécie de "assistência privada", para ter acesso a um lugar insalubre, repugnante e permeado por incertezas: "todas as manhãs, em Londres, 50 mil pessoas acordam sem a menor ideia de onde repousarão a cabeça na noite seguinte" (ENGELS, 2010, p. 75).

O relato trágico das condições de vida de crianças, adolescentes e familiares, efetuado por Engels (2010), se interpretado sem o devido cuidado, por uma abordagem senso comum, desprovido de maiores problematizações, pode levar ao simplismo de considerar tais situações como negligência individual ${ }^{14}$ e produto de ordem pessoal e moral, sobretudo porque a tendência da ideologia liberal, que sustenta a existência de ricos e pobres como algo natural, desconsidera a dimensão estrutural das desigualdades.

\section{Por uma interpretação marxista da infância e das políticas de abrigo}

Para Marx e Engels (1999), o primeiro ato histórico é a produção dos meios que permitam a satisfação de necessidades elementares, como a alimentação, a moradia e o vestuário. Ou seja, para se viver em sociedade 
algumas condições básicas, para além das necessidades alimentares, precisam ser satisfeitas, algo que não é garantido universalmente para todas as pessoas no modo de produção capitalista.

Os abrigos, sob as determinações do capitalismo, são espaços em que a luta de classes se materializa, como instituições assistenciais são "palco da luta de classes, da resistência da população às suas condições de vida" (IAMAMOTO, 2002). Para qualquer análise sobre abrigo, instituição marcada por construções ideológicas e por idealizações, é necessária, em primeiro lugar, identificar as contradições da concepção de proteção e as práticas de larga tradição na história, como a ajuda, o favor, o cuidado, a formação, a repressão, o controle e a violência. E, em segundo lugar, considerar a luta de classes, o racismo e o patriarcado como elementos fundamentais das relações sociais, "o gênero, raça/etnicidade e as classes sociais constituem eixos estruturantes da sociedade" (SAFFIOTI, 2015, p. 83).

$\mathrm{Na}$ ausência, provisória ou efetiva, de um ambiente familiar, a criança ou o adolescente, impossibilitado de vender a sua força de trabalho ou sob as ameaças constantes à integridade física tem no abrigo um dos espaços contraditórios de proteção ${ }^{15}$. Isto significa dizer que parte do capital alienado, no processo de produção, retorna não para o trabalhador em si, mas para toda a sociedade, e um percentual do fundo público ${ }^{16}$, destinado ao abrigo, permite à instituição atender provisoriamente necessidades que em princípio deveriam ser providas pelas famílias, ou seja, "o capital alienado no intercâmbio da força de trabalho é transformado em meios de subsistência, cujo consumo serve para reproduzir músculos, nervos, ossos, cérebro" (MARX, 1984, p. 157) não apenas dos trabalhadores existentes, mas dos trabalhadores que estão por vir.

A necessidade de uma interpretação marxista sobre o processo de institucionalização de crianças e adolescentes se justifica, pois os esforços empreendidos pela intelectualidade e as produções são canalizadas para defender garantia da convivência familiar, geralmente, exprimem uma concepção demasiadamente idealizada de família e do desenvolvimento individual, sem analisar os recursos insuficientes destinados para proteção social (LIMA, 2015) e as condições nas quais essas famílias garantem a proteção de crianças e adolescentes.

O Estatuto da Criança e do Adolescente, Lei n. ${ }^{\circ} 8.069 / 1990$, por exemplo, merece ser destacado. Muitas das críticas a essa normativa, efetuadas por conhecedores ou não, interpretam de maneira incompleta o artigo 23 , que sinaliza, justamente, um aspecto relacionado às famílias da classe trabalhadora e seus estratos pauperizados. A Lei, em oposição às práticas do período autoritário, prescreve que "a falta ou carência de recursos materiais não constitui motivo suficiente para a perda ou a suspensão do poder familiar" (BRASIL, 1990), isso, em outras palavras, significa dizer que, como aconteceu em história recente, seja nas primeiras décadas do século XX, com a criação do Primeiro Código de Menores, ou no período ditadura militar, com a Fundação Nacional de Bem Estar do Menor, onde crianças e adolescentes eram institucionalizados compulsoriamente e sem autorização de suas famílias pelo fato de serem pobres, com o ECA isso é teoricamente superado.

Contudo, o acolhimento ou abrigamento, mesmo que motivado por questões relacionadas à miséria, ao desemprego ou à vivência em situação de rua dos pais e/ou responsáveis, não enseja, obrigatoriamente, a separação da família e sua prole, pois essa medida de proteção deve garantir a convivência familiar e comunitária sem retirar a guarda da família de origem ${ }^{17}$, salvo em algumas excepcionalidades.

Em seu processo de desenvolvimento, a política de assistência social, firmada a partir de iniciativas estatais, só se realiza, de maneira mais ampla, quando o Estado assume progressivamente os encargos sociais com a sua inscrição na Seguridade Social (que reúne as políticas de previdência, saúde e assistência social) na Constituição Federal de 1988, na promulgação da Lei Orgânica da Assistência Social (LOAS, em 1993), e depois com a criação da Política Nacional de Assistência Social (PNAS, em 2004). A institucionalização tardia da assistência, que ultimamente tem conjugado políticas de alívio da pobreza e a centralidade da família, contribuiu para alicerçar a ideia de processualidade, provisoriedade e excepcionalidade do atendimento onde cabe ao abrigo ou à entidade de acolhimento institucional atender também às crianças e aos adolescentes dos segmentos pobres com outros direitos violados, pois quando se adota a medida protetiva de institucionalização, isso não constitui necessariamente a suspensão do poder familiar ${ }^{18}$.

Aos/às profissionais dos abrigos e unidades de acolhimento cabe ousar nas propostas de trabalho e questionar as desigualdades sociais, raciais e de gênero, expressar teoricamente uma determinada perspectiva de direitos humanos e traduzi-la para a população usuária, se organizar para subverter o caráter explorador do capital, produzindo conhecimento e subsidiando os movimentos sociais e conselhos de direitos. O movimento de construção de outra ordem societária, em sua complexidade, consiste em superar os mecanismos de adestramento do Estado burguês, impetrado em diversas instituições, que naturalizam e simplificam demasiadamente 
as condições precarizadas de vida. Isso cria as condições para que todas as crianças e adolescentes sejam introduzidas nas relações de troca e na lógica das mercadorias, ou seja, reiteram os "olhos amorosos com que as mercadorias piscam ao dinheiro" (MARX, 1983, p. 98).

A partir das leituras de Marx (1984, p. 187) e da concepção consagrada em Iamamoto e Carvalho (1996), subentende-se que as expressões da questão social na infância estão intimamente vinculadas ao processo de acumulação capitalista e abarcam múltiplos fenômenos sociais. Essas expressões incorporam também ambiguidades radicadas na noção liberal de proteção, pois do momento em que crianças e adolescentes, por vicissitudes da vida, não frequentam a escola, transitam ociosamente pelas ruas, ameaçam, danificam e se apropriam da propriedade privada ou cometem qualquer ato que, supostamente, atente contra a vida, passam a ser objeto de perseguição, criminalização e de estigmas por parte da sociedade e do Estado. A visibilidade de meninos e meninas de segmentos da classe trabalhadora e dos estratos pauperizados depende não só do reconhecimento de suas necessidades e, consequentemente, da intervenção dos Poderes Executivo, Legislativo e Judiciário, mas do seu ingresso numa organização que privilegia a sociabilidade urbano- industrial e o permanente direcionamento para sua adequação ao individualismo e às determinações do mercado.

Crianças e adolescentes, ao provocar a humanidade existente na sociedade, ao comover ou, até mesmo, ao incomodar cotidianamente a burguesia e a classe média, confrontam a arrogância envernizada e o combalido altruísmo, exigem (in)diretamente a necessidade da consolidação de políticas sociais universais e abrangentes. A adoção dessas políticas pode traduzir a necessária ruptura com formatos caritativos e repressivos de larga tradição, em maior ou menor grau, na história de cada país e sinaliza a prioridade de crianças e adolescentes no atendimento prestado nas áreas de saúde, assistência social, educação, cultura, lazer dentre outras, bem como na efetiva materialização das demandas sociais no orçamento público, na formulação e execução de planos, programas e projetos sociais.

Os interesses sociais antagônicos presentes na esfera da reprodução social são explicitados não apenas pela reivindicação política ou organização do segmento infantil-adolescente em movimentos sociais e em outras instâncias da sociedade civil, mas também por meio da rebeldia, ou seja, da ruptura com formatos idealizados de vida e da presença recalcitrante nos espaços urbanos, geralmente destinados às classes dominantes. A persistência e a tenacidade desses segmentos de classe insistem em se afirmar com suas características próprias, como pessoas livres, sujeitos de direitos e não apenas com uma cidadania amparada no mercado de consumo. E mesmo diante da exploração, dos conflitos redistributivos, dos preconceitos, das opressões e das crueldades e da exposição real das condições de vida desumanas, da fragmentada sociabilidade nas famílias, instituições, ruas, praças e favelas, essas crianças e adolescentes, sujeitos fundamentais para continuidade da civilização, ainda assim sorriem, resistem, sonham e lutam pela sobrevivência, para resgatar o olhar amoroso da humanidade e, por fim, para que seus direitos e necessidades sejam garantidos.

\section{Considerações finais}

Seja na roda dos expostos, nas famigeradas workhouses, nos grandes internatos ou mais recentemente nos abrigos, o processo de institucionalização acontece mediado pelas contradições da sociedade. $\mathrm{O}$ abrigo cumpre uma função social no modo de produção capitalista e sua superação, como idealizam inúmeras produções, é muito improvável nos marcos da sociabilidade burguesa. A faceta desigual das relações sociais aqui constituídas desde o período colonial, com o início do modelo escravocrata, até as metamorfoses do neoliberalismo, revela a culpabilização e a criminalização unilateral das famílias por não reunirem as condições objetivas para suprir as necessidades elementares de crianças e adolescentes. E as formas de institucionalização decorrem de vários fatores como o pauperismo, a busca desenfreada pela sobrevivência nas ruas, a violência socialmente produzida, as assimetrias da sociabilidade burguesa e de profundas desigualdades sociais e raciais no seio da sociedade contemporânea.

Essas instituições, geralmente, tão sucateadas contam com profissionais politizados e comprometidos com a qualificação do atendimento, mas sem a produção teórica para subsidiá-los e carecendo de organização coletiva que aponte para ampliação dos investimentos em políticas sociais e um horizonte de transformação. Assistentes sociais com sólida formação profissional conhecem a realidade de vida de crianças, adolescentes e famílias e embora sua atuação, mais imediata, não transforme concretamente a realidade, ela permite, ao menos, 
incidir decisivamente em diversas construções coletivas, na formação humana, nos processos de organização e de tomada de consciência dos segmentos que vivem e trabalham em abrigos.

Por fim, a organização desses segmentos de classe, a partir da produção e socialização do conhecimento e das práticas que se inspiram no legado teórico e político de Marx, podem mostrar um dos caminhos possíveis para a libertação das amarras que aprisionam a população usuária à dinâmica da proteção assistencial e aos esquemas perversos de institucionalização. Usando uma expressão dos meninos e meninas que vivem nos abrigos: "o papo é reto e tamo junto!" Portanto, uni-vos!

\section{Referências}

AZEVEDO, M. A. GUERRA, V. Infância e violência fatal em família. São Paulo: Iglu, 1998.

BARISON, M. Disciplina ou cidadania? Estatuto da Criança e do Adolescente e as representações de agentes educacionais de abrigos. O social em questão, Rio de Janeiro, ano 1, n. 2, 1997.

BATISTA, M. V. (org.). Abrigo: comunidade de acolhida e socioeducação. São Paulo: Núcleo de Estudos da Criança e do Adolescente, 2006.

BORGIANNI, E. Conselhos municipais da criança e do adolescente e a proposta de trabalho do abrigo. In: ENCONTRO ESTADUAL DE ABRIGOS DE SÃO PAULO, 1., 2004. São Paulo. Anais [...]. São Paulo, Centro de Capacitação e Incentivo à Formação, 2004. Não paginado.

BRASIL. [Constituição (1988)]. Constituição Federal de 1988. São Paulo: Revista dos Tribunais, 2000.

BRASIL. Lei no 8.069, de 13 de julho de 1990. Dispõe sobre o Estatuto da Criança e do Adolescente e dá outras providências. Brasília, DF: Presidência da República, 1990. Disponível em: http://www.planalto.gov.br/ccivil_03/leis/18069.htm. Acesso em: 2 set. 2020.

CARVALHO, M. do C. B. (Coord.). Trabalhando abrigos. Instituto de Estudos especiais, Centro Brasileiro para Infância e Adolescência CBIA, Caderno de Ação no 3, São Paulo, 1993.

CASTEL, R. As Metamorfoses da Questão Social: uma crônica do salário. Petrópolis: Vozes, 1998.

CASTELO, R. A. "Questão social” nas obras de Marx e Engels. Revista Praia Vermelha, Rio de Janeiro, v. 20, n. 1. 2010.

DIAS, E. F. A liberdade (im)possível na ordem do capital: reestruturação produtiva e passividade. São Paulo: IFCH/UNICAMP, 1999.

ENGELS, F. A situação da classe trabalhadora na Inglaterra. São Paulo: Boitempo, 2010.

HARVEY, D. A condição pós-moderna: uma pesquisa sobre as origens da mudança cultural. São Paulo: Loyola, 2000.

HUBERMAN, L. História da riqueza do homem. Rio de Janeiro: LTC, 2008.

IAMAMOTO, M.; CARVALHO, R. Relaç̃̃es sociais e Serviço Social no Brasil: esboço de uma interpretação histórico-metodológica. São Paulo: Cortez; Lima [Peru]: CELATS, 1996.

IAMAMOTO, M. Renovação e conservadorismo no Serviço Social: ensaios críticos. São Paulo: Cortez, 2002

JANCZURA, R. Abrigo para crianças e adolescentes como medida de proteção: uma controvérsia. Revista Políticas Públicas, São Luís, v. 12, n. 1, 2008.

LIMA, R.S. O mistério do orçamento dos abrigos no Rio de Janeiro. Revista Textos e Contextos, Porto Alegre, v. 14, n. 1, 2015.

LONDON, J. O povo do abismo:fome e miséria no coração do império britânico: uma reportagem do início do século XX. São Paulo: Ed. Fundação Perseu Abramo, 2004.

MALFITANO, A. P. S.; SILVA, T. V. da. Abrigo como medida de proteção para crianças e adolescentes: um levantamento bibliográfico PÓS-ECA. Revista Terapia Ocupacional, São Paulo, v. 25, n. 1, 2014.

MARX, K. O Capital: crítica da economia política. São Paulo: Abril cultural, 1983. v. 1, t. 1.

MARX, K. O Capital: crítica da economia política. São Paulo: Abril cultural, 1984. v. 1, t. 2.

MARX. K; ENGELS, F. A Ideologia Alemã. São Paulo: Hucitec, 1999.

MAURIEL, A. P. O. Capitalismo, políticas sociais e combate à pobreza. Ijuí/RS: Editora Unijuí, 2011.

NEVES. D. P. A perversão do trabalho infantil: lógicas sociais e alternativas de prevenção. Rio de Janeiro: Intertexto, 1999.

NUNES, D. G. Uma breve história da (in)visibilidade do abandono de crianças e adolescentes. In: FREIRE, S. (org.). Direitos humanos: violência e pobreza na América Latina. Rio de Janeiro: Letra e imagem, 2007.

PASTORINI, A. A categoria questão social em debate. São Paulo: Cortez, 2007.

PAULO NETTO, J. Cinco notas a propósito da "questão social”. Revista Temporalis, Brasília, ano 2, n. 3, 2001.

PEREIRA, P. Necessidades humanas: subsídios à crítica dos mínimos sociais. São Paulo: Cortez, 2000. 
PILOTTI, F. Crise e perspectiva da assistência à infância na América Latina. In: PILOTTI, F; RIZZINI, I. (org.). A arte de governar crianças: a história das políticas sociais, da legislação e da assistência à infância no Brasil. Rio de Janeiro: Instituto Interamericano Del Niño; Amais, 1995.

POLANYI, K. A grande transformação. Rio de Janeiro: Campus, 1980.

RIZZINI, I. (org.). Vidas nas ruas: crianças e adolescentes nas ruas: trajetórias inevitáveis? Rio de Janeiro: Ed. PUC-Rio, 2003.

SAFFIOTI, H. Gênero, Patriarcado violência. São Paulo: Expressão Popular, 2015.

SALES, M. A. (In)visibilidade Perversa: adolescentes infratores como metáfora da violência. São Paulo: Cortez, 2007.

SALVADOR, E.; ALVES, M. da C. L. O abandono dos direitos assistenciais do ECA na execução orçamentária. Revista Sociedade em Debate, Pelotas, $n^{\circ} 18,2012$.

SANTOS, B. R. dos. Enfrentamento da exploração sexual infanto-juvenil. São Paulo: Canone, 2010.

SILVA, M. L. O. Entre proteção e punição: Controle Sociopenal dos Adolescentes. Ed. da UNIFESP, 2011.

VEIGA, C. G. Crianças Pobres como Grupo Outsider e a Participação da Escola. Educ. Real, Porto Alegre, v. 42, n. 4, p. 1239-1256, 2017.

\section{Notas}

1 No texto, a expressão infância será utilizada abrangendo a situação de vida tanto de crianças como de adolescentes, pois embora seja um conceito envolto numa transitoriedade, "se localiza na dinâmica do desenvolvimento social e corresponde a uma estrutura social permanente" (PILOTTI, 1995, p. 25).

2 A Revista Serviço Social e Sociedade passou a ser publicada na versão on-line somente em 2009. E, para exemplificar, assistentes sociais também contam com publicações pontuais em livros e artigos: Carvalho (1993), Barison (1997), Borgianni (2004), Batista (2006), Nunes (2007) e Janczura (2008).

3 Dentre temas correlatos, os descritores utilizados nas buscas foram: "abrigo", "acolhimento à criança", "institucionalização", "orfanato", "convivência familiar e comunitária”, "família substituta” e "família acolhedora” (MALFITANO; SILVA, 2014, p. 95).

4 Para maior aprofundamento ver Iamamoto e Carvalho (1996), Pastorini (2007), Castelo (2010) e os artigos da revista Temporalis, em especial Paulo Netto (2001), também são fundamentais, assim como um autor não marxista, Robert Castel (1998), pela produção de metamorfoses da questão social: uma crônica da sociedade salário.

5 "Wilhem Wood, 9 anos de idade, tinha 7 anos e 10 meses quando começou a trabalhar [...]. 'Chega todos os dias da semana às 6 horas da manhã e para por volta das 9 horas da noite'. Portanto, 15 horas de trabalho para uma criança de 7 anos!” (MARX, 1983, p. 197).

6 Análises imediatas e baseadas na aparência dos fenômenos identificam como "negligentes" as famílias que submetem crianças a tal exposição, porém Marx (1984, p. 22) já realizava a crítica ao capital por "utilizar mulheres e moças nuas [...] tão de acordo com seu código moral e, sobretudo com seu livro-caixa" (MARX, 1984, p. 22).

7 "O trabalho forçado para o capitalista usurpou não apenas o lugar do folguedo infantil, mas também o trabalho livre no círculo doméstico, dentro de limites decentes, para a própria família (MARX, 1984, p. 23).

8 Estima-se que na primeira metade do século XVIII somavam-se na Europa 200 workhouses, que ofereciam alimento e moradia em troca de trabalho (VEIGA, 2017, p. 1242).

9 Para Huberman (2008, p. 145), o processo de acumulação primitiva do capital é a manifestação explícita da violência, da usurpação do sangue infantil e para além de envolver o comércio de seres humanos, nativos do continente africano, contemplou formas bizarras de traição, suborno, massacres e mesquinharias.

10 O termo pobre significava que todas as pessoas que passavam necessidades: "naturalmente isto incluía os indigentes, mas não apenas eles. Os velhos, os enfermos, os órfãos deviam receber cuidados numa sociedade que proclamava haver lugar para qualquer cristão no seu âmbito [...] a mendicância era severamente punida; a vagabundagem era uma ofensa capital" (POLANYI, 1980, p. 94).

11 A existência das instituições asilares foi e continua sendo funcional aos ditames do capital.

12 Promovem, na maioria das vezes, uma formação destinada a instrumentalizar, mediocremente, o seu público-alvo, estabelecendo uma espécie de resignação acerca das desigualdades e a passivização coletiva desses segmentos ou, resumidamente, a "neutralização das organizações proletárias" (DIAS, 1999, p. 102).

13 Londres, além de capital comercial, aglomerava 2,5 milhões de pessoas (ENGELS, 2010, p. 67). Um abrigo construído em 1844 , com capacidade para atender trezentas pessoas, recebeu 2.740 desabrigados na noite de sua inauguração.

14 A análise sobre negligência não é simples e deve-nos levar a indagar não apenas as condições estruturais de vida das famílias, pauperizadas ou não, mas o papel do cuidado entre homens e mulheres e as responsabilidades familiares. Azevedo e Guerra (1998) 
têm uma descrição do significado de negligência e sinalizam que ela não se aplica às condições que estão para além da realidade das famílias.

15 Que, por intermédio do fundo público ou de doações e a partir de uma dimensão assistencial e educativa objetiva a reprodução social.

16 É importante ressaltar que nos abrigos mantidos por entidades filantrópicas, o financiamento é realizado por meio dos subsídios de igrejas, por campanhas de doação, bazares e pela contribuição solidária de determinados indivíduos da sociedade.

17 Art. 28 - "A guarda é condição a colocação em família substituta far-se-á mediante guarda, tutela ou adoção, independentemente da situação jurídica da criança ou adolescente, nos termos desta Lei” (BRASIL, 1990).

18 De acordo com o ECA, art. 92 ( $1^{\circ}$ parágrafo) "o dirigente de entidade que desenvolve programa de acolhimento institucional é equiparado ao guardião, para todos os efeitos de direito" (BRASIL, 1990), mas isso não implica em destituição do poder familiar.

\section{Rodrigo Silva Lima}

rodrigorrod@hotmail.com

Doutor em Serviço Social pela Universidade do Estado do Rio de Janeiro (UFRJ)

Professor Adjunto do Curso de Graduação em Serviço Social e da Pós-Graduação em Serviço Social e

Desenvolvimento Regional da Escola de Serviço Social da Universidade Federal Fluminense (UFF)

\section{ESS/UFF}

Rua Professor Marcos Waldemar de Freitas Reis, sala 416, Bl. E, Campus Universitário do Gragoatá. Bairro São Domingos.

Niterói - RJ, Brasil

CEP: 24210-201

\section{Agradecimentos}

Lúcia Freire e Elaine Behring, minha gratidão pelas orientações e incentivo na produção acadêmica. Ana Paula Mauriel, meu reconhecimento pelo apoio e inspiração em minha vida.

Agência financiadora

Não se aplica.

Contribuições das autoras

Não se aplica.

\section{Aprovação por Comitê de Ética e consentimento para} participação

Não se aplica.

\section{Consentimento para publicação}

Consentimento do autor.

Conflito de interesses

Não há conflito de interesses. 